\title{
AS ESTRATÉGIAS DISCURSIVAS E MER- CADOLÓGICAS DA FOLHA DE S. PAULO PARA CAPTAÇÃO DE LEITORES
}

\author{
MARIA IVETE TREVISAN FOSSÁ \\ UNIVERSIDADE FEDERAL DE SANTA MARIA \\ SANTA MARIA, RIO GRANDE DO SUL, BRASIL \\ FOSSA@TERRA.COM.BR \\ FABRISE DE OLIVEIRA MÜLLER \\ UNIVERSIDADE FEDERAL DE SANTA MARIA \\ SANTA MARIA, RIO GRANDE DO SUL, BRASIL \\ FABRISE.SMA@TERRA.COM.BR
}

HTTP://DX.DOI.ORG/10.5902/2316882X25796 


\section{AS ESTRATÉGIAS DISCURSIVAS E MERCADOLÓGICAS DA FOLHA DE S. PAULO PARA CAPTAÇÃO DE LEITORES}

Resumo: A midiatização traz à tona uma nova postura do leitor diante da produção jornalística e o objetivo deste trabalho é analisar os contratos de comunicação estabelecidos pela Folha de S. Paulo na ambiência midiatizada. Os resultados indicam que os contratos de comunicação são firmados por meio de uma valorização da marca, do conteúdo do jornal e na tentativa de interação com o leitor.

Palavras-chave: Estratégias Discursivas. Marketing. Contratos de Comunicação. Leitor. Midiatização. Análise de Discurso.

\section{LAS ESTRATEGIAS DISCURSIVAS Y MERCADOLÓGICAS DE LA FO- LHA DE S. PAULO PARA LA CAPTACIÓN DE LECTORES}

Resumem: La mediación trae a la superficie una nueva postura del lector frente a la producción periodística y el objetivo de este trabajo es analizar los contratos de comunicación establecidos por la Folha de S. Paulo en el ambiente mediático. Los resultados indican que los contratos de comunicación son firmados por medio de una valorización de la marca, del contenido del periódico y en el intento de interacción con el lector.

Palabras clave: Estrategias Discursivas. Marketing. Contratos de Comunicación. Lector. Midiatización. Análisis de Discurso.

DISCURSIVE AND MARKET STRATEGIES OF FOLHA DE S. PAULO IN PROSPECTING READERS

Abstract: Media coverage brings up a new attitude from readers concerning journalistic production, considering the proposals, the following research aims to analyze the communication contracts established by the Folha de S. Paulo in media environment to prospect readers. The results indicate that communication contracts are signed by a brand valuation and newspaper content, attempting to interact with the reader.

Keywords: Discursive strategies. Marketing. Communication Contracts. Reader. Media Coverage. Discourse Analysis. 


\section{INTRODUÇÃO}

Independente da plataforma, impressa ou digital, o jornal é uma fonte de informação credível, se comparado a outros meios de comunicação de massa, servindo de base para o conhecimento comum da sociedade e, até mesmo, como meio de informações para outros veículos de comunicação. Porem, desde o advento da internet o meio jornal tem dado seguidas demonstrações de que sentiu o golpe da nova concorrência. Os índices apontam uma diminuição de 1,9\% de leitura em impressos no país, de acordo com o Instituto Verificador de Circulação (IVC)'. Uma das principais modificações é o oferecimento das notícias em tempo real na rede, sendo o acesso limitado, gratuito ou por meio de assinaturas para pagantes. É diante dessa realidade e de uma busca incessante por respostas que se dá a crise de identidade do jornalismo impresso.

Com a necessidade de reinvenção, o jornal impresso procura manter o seu público leitor e ainda atrair novos públicos para o consumo. Entre tantas questões que favorecem o impresso, a credibilidade parece estar associada à confiança na fonte produtora das informações, pelo fato de o leitor saber que o jornal é produzido por profissionais, o que nem sempre se concretiza no universo on-line.

\section{OBJETIVOS}

É na totalização de esforços, de diferentes setores, que, até então, direcionavam suas estratégias para bem informar (redação, discurso), ou bem vender (marketing), que pode estar configurada a realidade do contrato de comunicação do jornal impresso, no contexto da midiatização. Assim, o objetivo geral desta tese é analisar os contratos de comunicação estabelecidos pela Folha de S. Paulo na ambiência midiatizada para a captação dos leitores. As etapas da pesquisa são expressas a partir dos seguintes objetivos específicos: a) identificar os modos de contato da FoIha de S. Paulo (jornal impresso) com seus leitores; b) investigar as lógicas discursivas que regem as aproximações entre jornal impresso e o leitor e c) investigar que estratégias de marketing são utilizadas pelo jornal impresso para enfrentar a concorrência, com outras mídias e plataformas, e 
captar os leitores.

Considerando-se que a Folha de S. Paulo, é uma empresa com mais de 90 anos, torna-se interessante e importante estudá-la, pelas diversas reformas editoriais que o jornal enfrentou, a representatividade do veículo em termos de assinantes e leitores e a preponderância diante dos demais concorrentes impressos.

\section{CONSIDERAÇÕES METODOLÓGICAS}

Esta pesquisa considerou a relação dinâmica, particular, contextual e particular entre o objeto de estudo, a Folha de S. Paulo e a autora da tese, por isso, conforme sugere Michel (2009) é qualitativa. A interpretação do corpus considera o contexto atual, os fatos, a realidade. A coparticipação dos respondentes da pesquisa se deu através de entrevistas em profundidade com o roteiro semiestruturado. Considerando, que foram realizadas entrevistas, a comprovação dos fatos apresentados não se dá numericamente, e sim, a partir de uma análise detalhada das informações.

A primeira etapa do trabalho foi exploratória, pois se deu a partir de levantamentos bibliográficos sobre a temática, com buscas a partir das palavras-chave: análise de discurso, estratégias de discurso, marketing, leitor e midiatização. O resultado desta etapa foi a revisão bibliográfica e a composição de capítulos teóricos analisando os contratos de comunicação, o leitor modelo, a analítica da midiatização, as estratégias de captação discursivas e as estratégias de marketing.

Os dados primários partiram então da pesquisa das publicações da FoIha e das entrevistas. Já, os dados secundários foram obtidos através de consultas ao site e redes sociais do jornal e de outras produções cientificas que foram consultadas durante a pesquisa do estado da arte. Também foi realizada uma pesquisa documental, por meio de observação do site do jornal, da fanpage no Facebook, leitura do manual de redação, das publicações da marca e estado da arte.

A coleta de dados contou com entrevistas em profundidade, realizadas em datas diferentes. Uma primeira visita à sede da Folha de S. Paulo ocorreu no mês de dezembro de 2014, antes da etapa de qualificação do projeto de tese, e após em maio de 2016 com questionamentos sugeridos pela banca que analisou o projeto. As entrevistas realizadas permitiram a pesquisadora explorar amplamente a questão problema, pois o roteiro foi

Rev.Cad.Comun. Santa Maria, v.21, n.2, art 7, p. 130 de 137, maio/ago.2017 
semiestruturado.

Em uma primeira etapa desta tese, foram arquivadas as 12 capas do jornal Folha de S. Paulo. As capas foram obtidas a partir do acervo do jornal, que é composto de 90 anos de exemplares do jornal, resultado, em sua maior parte, da conversão dos exemplares em papel para o formato digital por intermédio da cópia em microfilme. As edições mais recentes da Folha de S. Paulo provêm de versões em formato pdf extraídas diretamente do processo de publicação do jornal². Para as estratégias mercadológicas, a observação se deu a partir da edição completa do jornal, ambas no mesmo período, 14 de setembro a 24 de setembro de 2015.

Essa tese teve como base a teoria da sociolinguística, do contrato de comunicação desenvolvida por Charaudeau (2010; 2013) e parte da análise semiolinguística. O método tem sua origem na semiose, a partir da qual a construção de sentido e a configuração se dá através de uma relação forma-sentido sob a responsabilidade de um sujeito intencional em um processo que compreende o desejo de influência social, envolto em um quadro de ação. $O$ discurso constitui-se, pois num campo de disciplina próprio, com um conjunto de métodos e técnicas que lhe são muito específicos. Ele está contextualizado em uma problemática das relações e das estratégias de poder e tem a capacidade de "fazer agir", de modificar as relações entre os parceiros linguísticos (LANDOWSKI, 1992). Quem redige pode estabelecer deveres e criar expectativas em quem lê. Ao pesquisador compete entender além da mensagem e captar as interações dadas pelo discurso entre os sujeitos que se inscrevem e os que se reconhecem nele (LANDOWSKI, 1992).

Com o suporte da revisão teórica, foram mapeados como elementos de análise as estratégias discursivas e mercadológicas, observados, respectivamente, nas capas da Folha e na edição completa do Jornal. O período de análise compreendeu as 12 edições impressas do jornal de 14 de setembro a 25 de setembro de 2015, escolhidas de modo aleatório e observadas a partir do dispositivo flip33. Também Também foram realizadas entrevistas semiestruturadas com o gerente de circulação da Folha, com a

2 Disponível em: <http//acervo.folha.com.br/acervo/>. Acesso em: 03 dez. 2015.

3 A navegação flip é uma ferramenta que permite ao leitor ler o jornal exatamente da forma como é o impresso, com a mesma diagramação e disposição de páginas. É como se o jornal fosse folheado, só que no meio digital.

Rev.Cad.Comun. Santa Maria, v.21, n.2, art 7, p. 131 de 137, maio/ago.2017 
gerente de treinamento, com um editor e como o gerente de marketing e comunicação, mapeando questões referentes à temática da tese.

\section{PRINCIPAIS RESULTADOS}

A capa da Folha constitui-se em um elemento importante no estabelecimento do contrato de comunicação com o leitor. Ela apresenta um resumo do que a empresa considera importante ao leitor saber. Diante da exigência de tempo do mesmo, a capa hierarquiza os assuntos através da manchete e fotos e chamadas. A importância se dá pelo tamanho da fonte, uso de negrito, imagens inéditas, chocantes e o uso de leads, já resumindo o assunto para o leitor.

O jornal valoriza a força de sua marca e, por meio dela, cria uma identidade a ser reconhecida pelo público. Evidencia isso através do seu posicionamento e as campanhas que reforçam como a Folha quer ser vista pelos leitores. O jornal estabelece-se como um veículo de comunicação a serviço do Brasil, o que é reforçado pela divulgação da sua abrangência e tiragem.

Nas redes sociais, existe a produção de notícias 24 horas por dia. $\mathrm{Na}$ capa impressa, o horário de fechamento da redação e impresso, mas as postagens online seguem 24 horas por dia, totalizando uma média de 50 publicações (Facebook). Tal postura pode indicar o desejo da Folha de informar a cada minuto. Assim, o jornal busca firmar sua identidade como veículo que divulga notícias e fatos em 'primeira mão'.

As posturas declaradas pela Folha indicam a autonomia e confiança do jornal para definir as pautas e como os assuntos devem ser abordados e discutidos pelos leitores. Para tanto, cercam-se de materiais inéditos, informações exclusivas e saem das redações em busca do 'furo' de notícia. A opção pela diversidade de colunistas indica a estratégia de adesão, onde a diversidade possa satisfazer ao máximo de leitores. Também a simplificação do conteúdo é uma estratégia para 'facilitar' a vida do leitor (não pode ter dificuldades em encontrar o conteúdo que deseja ler). Na internet, tem a opção de visualização como se estivesse lendo o jornal impresso, ou então, pode optar pelas informações da forma em que estão dispostas no site. Além disso, a capa orienta exatamente onde está o conteúdo, a reportagem, conduz os caminhos do leitor na parte interna do jornal.

As pautas devem ser inéditas e preferencialmente com conteúdo exclusivos que só a Folha tem. Para isso, estão atentos aos boatos que sur-

Rev.Cad.Comun. Santa Maria, v.21, n.2, art 7, p. 132 de 137, maio/ago.2017 
gem nas redações. As pautas devem afetar a vida do maior número de leitores possível. Se o conteúdo for inédito e nenhum concorrente terá acesso, deve ficar reservado ao jornal impresso e, só após isso, será veiculado na internet.

O posicionamento da Folha tenta diariamente reforçar as características de plural e apartidário. Mas mais que isso, assume um papel político no que tange evidenciar aos leitores que é capaz de selecionar e indicar o que é importante para se saber, o que se deve ler.

A vulgarização é também uma das estratégias de captação, contar de modo simples, valer-se de categorias de pensamento, lugares-comum, são os recursos que objetivam facilitar a inteligibilidade do jornal. Mesmo dizendo não subestimar a inteligência do leitor, se vale de esquemas, gráficos, desenhos, infográficos, sintetizando ainda mais para o público aspectos que já foram, segundo o jornal, escritor de foram analítica na reportagem. O amálgama - outro recurso de simplificação que a Folha usa, colocando várias reportagens sob o mesmo selo, como por exemplo, "Brasil em Crise", também é utilizado com frequência

A organização objetiva dar a percepção ao leitor de que existe uma interação. Seja através do painel do leitor, da forma de tratamento 'excelentíssimo leitor', dos textos da ombudsman. Ao mesmo tempo em que declara que o 'leitor não é necessário para a sugestão de pautas', diz que ele é valorizado e que uma das preocupações da redação é com as respostas aos comentários dos leitores. Ainda assim, a transparência da relação entre produção e recepção passa pelo filtro de editores e ombudsman.

A escolha entre a divulgação da notícia na plataforma impressa ou na plataforma digital. A Folha estabelece diferenciações no que concerne à divulgação das matérias nas suas plataformas on-line e impressa. Ela reserva matérias jornalísticas com maior relevância e exclusividade para o jornal impresso. De outro modo, as informações que precisam ser imediatamente divulgadas são publicadas na sua versão digital e nas mídias sociais digitais do jornal.

São os leitores que sustentam o jornal - não somente por questões financeiras, mas também pela audiência a cada edição. Assim, existe um cuidado com a relação que se estabelece com os leitores primários (aquele que compra o jornal ou assina) e secundários (que leem o jornal, mas não têm acesso). A Folha parece produzir um jornal direcionado a um público que é informado, de formação superior, e que deseja uma leitura 
completa, que acredite ser ética e isenta de interferências políticas e econômicas. O contrato de leitura estabelece que a Folha trabalha com temas polêmicos e com 'furos' de reportagens e que traz aos seus públicos uma notícia que contém diferentes opiniões e versões sobre um mesmo tema. A própria reputação do jornal deve ser um dos facilitadores para que depoimentos, relatos e dados sejam repassados por fontes de todos os meios sociais. Ainda assim, o jornal enfrenta desafios diante dos cenários de midiatização.

Em entrevistas realizadas com os profissionais de Folha, os relatos evidenciam a necessidade de que: o leitor do digital migre para o impresso; o público consuma o jornal através das duas fontes; os leitores do jornal impresso também migrem para a plataforma digital. Para atender a essas demandas, as plataformas on-line passaram a não liberar o acesso total ao seu conteúdo, como faziam anteriormente, oferecendo apenas acesso a poucos conteúdos. Os profissionais de gestão chamam isso de período de degustação - no qual a estratégia é permitir que os leitores conheçam e se acostumem com o formato para que, depois, tornem-se consumidores.

A midiatização na comunicação traz alterações ao meio impresso, pois a democratização da internet possibilitou um acesso rápido e fácil ao mundo das notícias. De repente, um público jovem, que nasceu sob o domínio da sociedade da informação, busca, como fonte principal de suas notícias, os meios digitais. É com esses argumentos que o posicionamento da mídia vem se alterando. E as estratégias se tornam ainda mais importantes, uma vez que, diante da dinâmica, ninguém sabe ao certo precisar o que o leitor "fará" com o jornal impresso. As pesquisas já indicam a queda no consumo do produto, e os veículos investem com ênfase no on-line sem desacreditar do jornal impresso.

\section{CONCLUSÕES}

O trabalho de tese realizado conduz a reflexões sobre a circulação do jornal impresso, seus leitores, a produção, os modos de fazer e as estratégias que são utilizadas com o objetivo de captar o leitor. É em meio a uma mudança de cenário, com variáveis ambientais influenciando diretamente o desempenho do negócio, que as empresas jornalísticas, buscam adaptar-se e sobreviver. Neste contexto, a midiatização parece estar interferindo e conduzindo os veículos de comunicação a tomada de decisões ime-

Rev.Cad.Comun. Santa Maria, v.21, n.2, art 7, p. 134 de 137, maio/ago.2017 
diatas frente ao seu leitor.

Sabe-se que o processo de midiatização marca a nova realidade dos meios de comunicação por vários motivos, especialmente, por caracterizar um contexto onde as tecnologias de informação transformam o acesso à notícia. De forma simplista, seria como dizer que os leitores não esperam a edição diária do jornal para ter a informação e acessam conteúdos digitais produzidos à luz do imediatismo e da instantaneidade. Os próprios veículos impressos acompanham essa tendência, valendo-se de recursos para estar em contato com o leitor minuto a minuto através de postagens no Facebook, como pode ser visto no caso da Folha.

Soma-se a isso o desafio das empresas de modo geral de conhecer o universo de consumidores acostumados, até pouco tempo atrás, a consumir apenas meios massivos, como a televisão, o rádio e o jornal. Neste cenário anterior, o mapeamento demográfico dos leitores era fosse suficiente para nortear as estratégias das mídias. Hoje, essas pesquisas de público tornaram-se ultrapassadas, diante das tantas as plataformas de acesso a conteúdo. Configurar novas estratégias de conhecer o perfil e hábitos dos leitores torna-se importante neste cenário justamente pelo desconhecimento deste público incidir em riscos para o negócio.

É em meio a incertezas e questionamentos que os jornais impressos trabalham para este novo leitor, sem um redesenho preciso de como serão as edições impressas daqui a 5 ou 10 anos. É um novo leitor, porque se identificam mudanças quanto às escolhas de plataformas para se informar (os jovens não querem ler o jornal impresso declara a Folha), que aprimoram aspectos ligados à instantaneidade e interatividade entre jornal e leitores. E é para captar este leitor que os jornais impressos, especificamente, se munem de estratégias que perpassam o discurso e as ações mercadológicas. Nesse raciocínio, o objetivo geral do estudo foi analisar que contratos são estabelecidos pela Folha de S. Paulo na ambiência midiatizada para a captação dos leitores. Isso foi possível por meio da identificação do contrato de comunicação do jornal com seus os leitores, da investigação das lógicas discursivas e das estratégias de marketing que regem a captação de leitores, adotadas pelo comercial, marketing e comunicação da Folha de S. Paulo.

Em termos mercadológicos, o jornal busca a interação com o leitor, seja através de eventos, ou de interfaces virtuais, mas acima da tudo, o jornal embasa suas táticas na valorização da marca, por isso investe na

Rev.Cad.Comun. Santa Maria, v.21, n.2, art 7, p. 135 de 137, maio/ago.2017 
reputação do veículo, na qualidade dos profissionais que a compõem (colunistas) e sendo fonte de referência para outros campos sociais (citada em pesquisas políticas, por pares, etc.).

Ainda nessa ambiência, preconiza-se um novo formato para a produção jornalística impressa, que se assemelha a produção jornalística em plataformas virtuais, unificando ambas, ainda que os leitores possam ter características diferentes. Tal assertiva também é confirmada e pode ser visualizada em função de textos resumidos, da unificação das redações do jornal impresso e virtual, das decisões quanto a pautas que devem ser publicizadas em tempo real ou devem aguardar a edição impressa.

\section{REFERENCIAS}

CHARAUDEAU, P. Uma teoria dos sujeitos da linguagem. In: MARI, H.; MACHADO, I. L.; MELLO, R. de (orgs). Análise do discurso: fundamentos e práticas. Belo Horizonte: Núcleo de Análise do Discurso - FALE/UFMG, 2001.

CHARAUDEAU, P. Linguagem e discurso: modos de organização. Trad. Angela Corrêa e Ida Lúcia Machado. 2 ed. São Paulo: Contexto, 2010.

CHARAUDEAU, P. Discurso das mídias. Trad. ngela M. S. Corrêa. 2 ed. 2 reimpressão. São Paulo: Contexto, 2013.

CHARAUDEAU, P. ; MAINGUENEAU, D. Dicionário de análise do discurso. 2 ed. São Paulo: Contexto, 2006.

FAUSTO NETO, A. Fragmentos de uma Analítica da Midiatização. Revista Matrizes. v. 1, n. 2, p. 89-105, abr. 2008.

FAUSTO NETO, A. Contratos de leitura: entre regulações e deslocamentos. In: XXX CONGRESSO BRASILEIRO DE CIÊNCIAS DA COMUNICAÇÃO, 2007, Santos. Disponivel em: http://www.intercom.org.br/papers/nacionais/2007/resumos/R1528-2.pdf. Acesso em 03 nov. 2015.

HJARVARD, S. Midiatização: teorizando a mídia como agente de mudança social e cultural. Revista Matrizes, v. 5, n. 2, p. 53-91, jan./jun. 2012.

LANDOWSKI, E. A sociedade refletida: ensaios de sociossemiótica. São Paulo: EDUC/ Pontes, 1992. 
MAINGUENEAU, D. Análise de textos de comunicação. Tradução: Cecília P. de Souza-e-Silva e Décio Rocha. 6. ed. São Paulo: Cortez, 2013.

MAINGUENEAU, D. Gênese dos discursos. Tradução: Sírio Possenti. São Paulo: Parábola Editorial, 2008.

MAINGUENEAU, D. Estudos de discurso e análise do discurso. In: Discurso e análise do discurso. São Paulo: Parábola, 2015.

VÉRON, E. Fragmentos de um tecido. São Leopoldo: UNISINOS, 2004.

VERÓN, E. Esquema para el análisis de la mediatizacion. Revista Diálogos, Buenos Aires, n. 48, 1997.

\section{Ivete Trevisan Fossá}

Doutora em Administração pela Universidade Federal do Rio Grande do Sul. Mestre em Comunicação Social pela Universidade Metodista de São Paulo. Professora associada, nível III, da Universidade Federal de Santa Maria E-mail:fossa@terra.com.br

\section{Fabrise de Oliveira Müller}

Doutora em Comunicação Midiática pela Universidade Federal de Santa Maria (UFSM). E-mail: fabrise.sma@terra.com.br.

A dissertação que originou este artigo foi orientada pela Dra. Maria Ivete Trevisan Fossá e defendida em 21/12/2016, na linha "Mídias e estratégias comunicacionais" do POSCOM-UFSM

RECEBIDO EM: 06/02/2017

ACEITO EM: 06/04/2017 